\title{
Reduced dosage of the modifiers of epigenetic reprogramming Dnmt1, Dnmt3L, SmcHD1 and Foxo3a has no detectable effect on mouse telomere length in vivo
}

\author{
Amity R. Roberts • Marnie E. Blewitt • \\ Neil A. Youngson • Emma Whitelaw $\cdot$ Suyinn Chong
}

Received: 15 March 2011 / Accepted: 18 March 2011 /Published online: 7 May 2011

(C) The Author(s) 2011. This article is published with open access at Springerlink.com

\begin{abstract}
Studies carried out in cultured cells have implicated modifiers of epigenetic reprogramming in the regulation of telomere length, reporting elongation in cells that were null for DNA methyltransferase DNA methyltransferase 1 (Dnmt1), both de novo DNA methyltransferases, Dnmt3a and Dnmt $3 b$ or various histone methyltransferases. To investigate this further, we assayed telomere length in whole embryos or adult tissue from mice carrying mutations in four different modifiers of epigenetic reprogramming: Dnmt1, DNA methyltransferase 3-like, structural maintenance of chromosomes hinge domain containing 1, and forkhead box $O 3 a$. Terminal restriction fragment analysis was used to compare telomere length in homozygous mutants, heterozygous mutants and wild-type littermates. Contrary to expectation, we did not detect overall lengthening in the mutants, raising questions about the role of epigenetic processes in telomere length in vivo.
\end{abstract}

Communicated by J. Karlseder

Electronic supplementary material The online version of this article (doi:10.1007/s00412-011-0318-9) contains supplementary material, which is available to authorized users.

A. R. Roberts $\cdot$ N. A. Youngson $\cdot$ E. Whitelaw $\cdot S$. Chong $(\bowtie)$ Epigenetics Laboratory,

Queensland Institute of Medical Research,

Herston, QLD 4006, Australia

e-mail: Suyinn.Chong@qimr.edu.au

A. R. Roberts

School of Biomolecular and Physical Sciences,

Griffith University,

Nathan, QLD 4111, Australia

\section{E. Blewitt}

Molecular Medicine Division,

Walter and Eliza Hall Institute of Medical Research,

Parkville, VIC 3050, Australia

\section{Introduction}

Telomeres are nucleoprotein structures located at the ends of chromosomes that perform a capping function to maintain chromosome stability and integrity. In vertebrates, telomeres contain tandem repeats of the TTAGGG sequence and are bound by many associated proteins. These proteins are collectively known as the shelterin complex or telosome, and they mediate the capping function of the telomere along with telomere length regulation (Blackburn 2001; de Lange 2005). Telomere length can also be regulated by the action of telomerase, a reverse transcriptase that adds telomeric repeats to the ends of chromosomes (Collins and Mitchell 2002; Blasco 2005). In humans, telomerase activity is detected in adult testes and ovaries, but not in other tissues (Wright et al. 1996). In Mus musculus, telomerase activity is relatively high in testes and liver, detectable in kidney and spleen, but not detectable in brain tissue (Prowse and Greider 1995). Telomerase is also active in $85 \%$ of human cancer cell lines (Shay and Bacchetti 1997). Telomere length in the remaining $15 \%$ of human cancers is maintained by the so-called alternative lengthening of telomeres (ALT) mechanism (Muntoni and Reddel 2005; Cesare and Reddel 2010). ALT-mediated lengthening of telomeres is associated with increased rates of telomeric recombination events (Muntoni and Reddel 2005).

Mammalian telomeres possess epigenetic marks that are characteristic of constitutive heterochromatin (Schoeftner and Blasco 2010). Previously published work suggests that a less compacted heterochromatic telomere structure leads to deregulation of telomere length. This comes from studies of cells deficient in a variety of repressive epigenetic marks including cytosine methylation, histone $\mathrm{H} 3$ lysine 9 trimethylation and histone $\mathrm{H} 4$ lysine 20 trimethylation. The cells used were $D N A$ methyltransferase 1 (Dnmt1) null or Dnmt3a and Dnmt3b 
double-null ES cells (Gonzalo et al. 2006), Suv39h1 and Suv39h2 double-null mouse embryonic fibroblasts (MEFs) and ES cells (Garcia-Cao et al. 2004) and Suv4-20h2 null or Suv4-20h1 and Suv4-20h2 double-null MEFs and ES cells (Benetti et al. 2007). Telomere elongation was reported in each case, and the involvement of ALT in this process was further suggested by increased recombination between telomeric sister chromatids and an increase in the number of ALTassociated promyelocytic leukaemia bodies, which contain telomeric repeats and telomere-binding proteins (Gonzalo et al. 2006; Benetti et al. 2007).

The studies mentioned above were performed on cultured cells, and we were interested to know whether altered epigenetic reprogramming affects telomere length in vivo. Here, we have examined the effects of reduced dosage of proteins involved in establishing and maintaining epigenetic marks, on telomere length using whole embryos or adult tissue. We analysed mice deficient for Dnmt1, Dnmt3L, structural maintenance of chromosomes hinge domain containing 1 (SmcHD1) or forkhead box O3a (Foxo3a). Dnmt1 is the maintenance DNA methyltransferase in the mouse (Bestor et al. 1988). Dnmt3L is a catalytically inactive protein that partners with Dnmt3a and Dnmt3b and has a major role in establishing imprints in the germ cells (Webster et al. 2005; Hata et al. 2002; Bourc'his et al. 2001). SmcHD1 is a member of the SMC family of proteins and is involved in X-inactivation, the epigenetic silencing of one of the two $\mathrm{X}$ chromosomes in female mammals (Blewitt et al. 2008). Foxo3a is a transcription factor known to act as a transcriptional repressor (Youngson et al. 2011). A number of these mutant mice were produced in a sensitised $N$-ethyl $-N$ nitrosourea (ENU) screen for modifiers of epigenetic reprogramming (Chong et al. 2007; Blewitt et al. 2008). This screen uses a GFP transgene that is particularly sensitive to epigenetic silencing, to identify genes elsewhere in the genome that when mutated alter the extent of silencing at the transgene locus (Blewitt et al. 2005). Mutations in Dnmt1, Smchd1 and Foxo3a have been produced in this screen (Chong et al. 2007; Blewitt et al. 2008; Youngson et al. 2011).

In our study, telomere length was measured using conventional Southern blot terminal restriction fragment (TRF) analysis, which generates TRFs that contain the entire telomeric sequence and a small proportion of subtelomeric sequence that remains attached following enzyme digestion with a frequent cutter (Kimura et al. 2010). The incorporation of subtelomeric sequence into the TRFs leads to a slight overestimation of telomere length. However, this slight overestimation is not detrimental to our analysis, as we are not aiming to measure the true length of mouse chromosomes. We are aiming to compare telomere lengths among individuals of different genotypes.
We do not detect an increase in overall telomere length in mutant compared to wild-type individuals.

\section{Results}

Reduced dosage of Dnmt1 does not affect overall telomere length in vivo

Dnmt1 is a maintenance DNA methyltransferase, and its complete loss has previously been reported to lead to telomere elongation in cultured ES cells (Gonzalo et al. 2006). These ES cells were homozygous for the Dnmt ${ }^{c}$ knockout allele, which results in a total loss-of-function (Lei et al. 1996). We examined inbred C57BL/6 embryos homozygous for a Dnmt1 ${ }^{n}$ allele and compared them with $D_{n n t} 1^{+/ n}$ and Dnmt $1^{+/+}$littermates. The Dnmt ${ }^{n}$ allele is an almost total loss-of-function mutation leading to severely reduced enzymatic activity of the protein ( $\mathrm{Li}$ et al. 1992). There is a three-fold decrease of genomic methylcytosine content in Dnmt $1^{n / n}$ mutants compared to wild type, which is slightly less than the decrease seen in $D n m t 1^{c / c}$. Homozygosity for $D n m t 1^{n}$ or for $D n m t 1^{c}$ is associated with embryonic lethality around 9.5 days post-coitum (p.c.; Li et al. 1992). We measured telomere length in embryos carrying the Dnmt $1^{n}$ allele at 8.5 days p.c., using TRF analysis. We digested the genomic DNA with DpnII, which does not recognise (TTAGGG)n and is not sensitive to DNA methylation. In contrast to the study using ES cells (Gonzalo et al. 2006), we found that the overall length of the TRFs from embryos homozygous for the $D n m t 1^{n}$ allele was similar to that seen in wild-type littermates (Fig. 1a). One possible reason for the discrepancy could be the use of a different restriction enzyme for genomic DNA digestion. We used DpnII, a methylation-insensitive enzyme, while the previous study used $M b o \mathrm{I}$, a methylation-sensitive isoschizomer (Gonzalo et al. 2006). We repeated our experiment on different individuals using $M b o \mathrm{I}$ digestion, but again no dramatic changes in TRF length were observed in Dnmt $1^{n / n}$ embryos (Fig. 1b).

TRF analysis was also performed on a second, independent Dnmt1 mutant mouse line, Dnmt1 ${ }^{\text {MommeD2 }}$. This mouse line was produced in the ENU mutagenesis screen for modifiers of epigenetic reprogramming and has been maintained on an inbred FVB/NJ strain background (Chong et al. 2007). As expected, the mutation is associated with an increase in the expression of the GFP reporter transgene. Dnmt1 protein levels are severely reduced (less than $5 \%$ of wild type) in homozygous mutant 9.5 days p.c. embryos, they die at a similar time point to those carrying the Dnmt $1^{n}$ or Dnmt $1^{c}$ allele and they display similar levels of genome-wide DNA hypomethylation (Chong et al. 2007). While we find that the 
Fig. 1 Telomere length in

whole embryos deficient for

Dnmt1. a TRF results are shown

for $D n m t 1^{+/+}, D n m t 1^{+/ n}$ and

Dnmt $1^{n / n}$ embryos at 8.5 days

p.c. following digestion with the

methylation-insensitive enzyme,

DpnII. b TRF results are shown for different $D n m t 1^{+/+}, D n m t 1^{+/ n}$ and Dnmt $1^{n / n}$ embryos at 8.5 days p.c. following digestion with the methylation-sensitive enzyme, $M b o$ I. c TRF results are shown for Dnmt1 $1^{+/+}$,

$D n m t 1^{+/ M D 2}$ and Dnmt1 $1^{M D 2 / M D 2}$ embryos at 9.5 days p.c.

following digestion with $D p n I I$. MD2 MommeD2 a

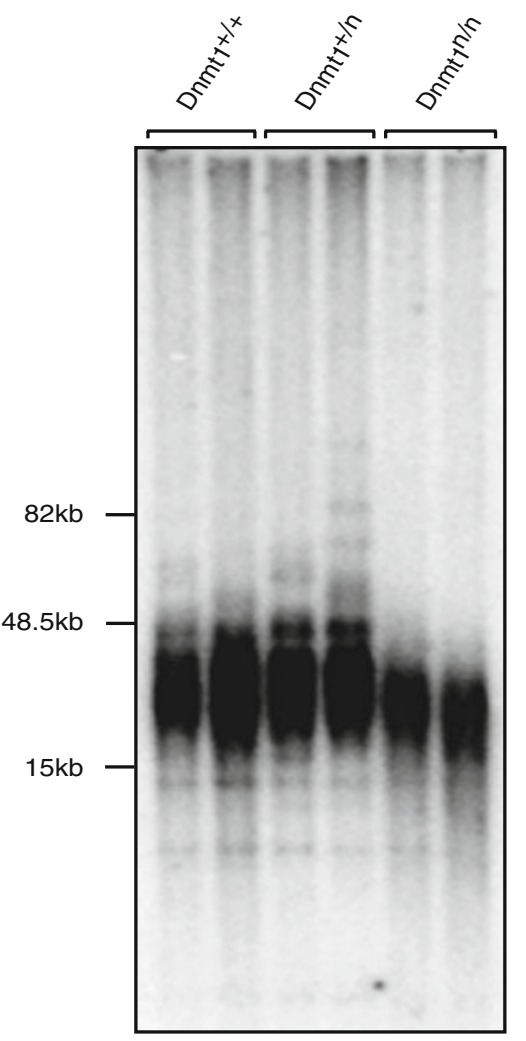

b

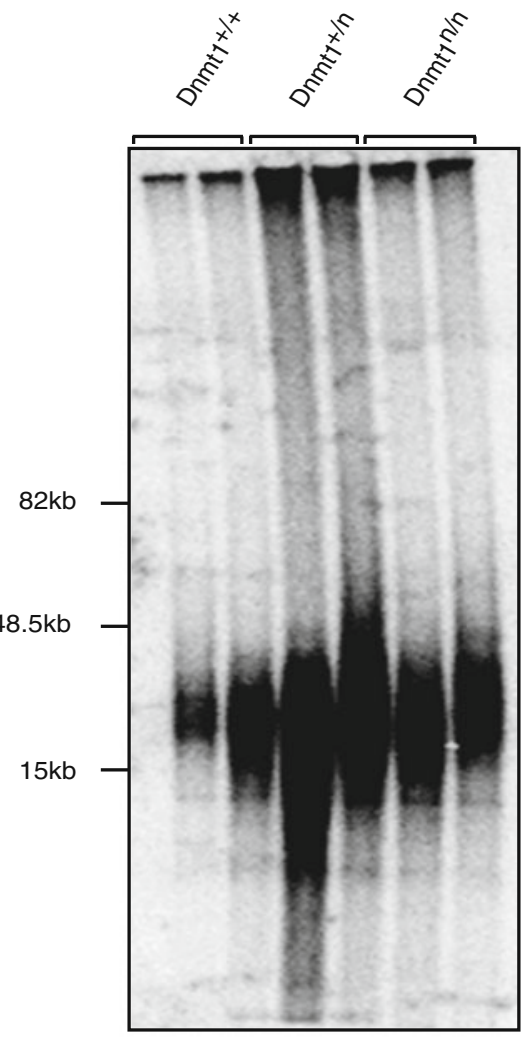

C

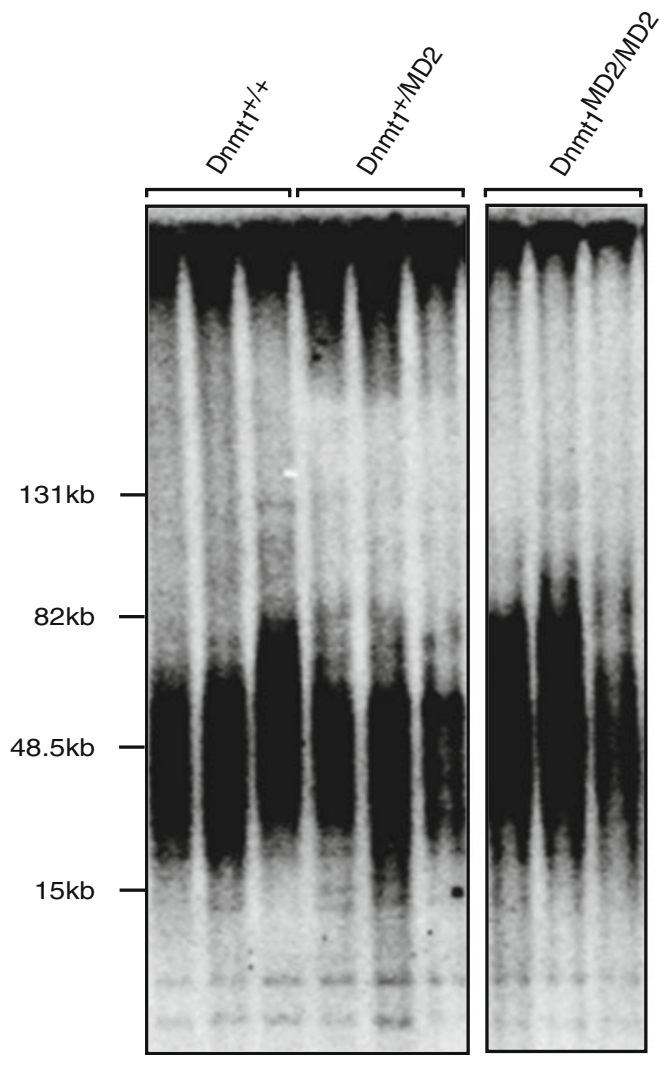


FVB/NJ strain has longer telomeres than the C57BL/6 strain, again there was no overall difference in telomere length between the homozygous mutant Dnmt1 ${ }^{\text {MommeD2 }}$ embryos and the wild-type littermates (Fig. 1c).

Lack of Dnmt3L does not affect overall telomere length in vivo

Dnmt3L is a homolog of Dnmt3a and Dnmt3b that lacks catalytic activity; is highly expressed in the early embryo, ES cells and gametes and is known to have a critical role in imprinting. It is thought to function as a co-regulator of both Dnmt3a and Dnmt3b (Hata et al. 2002). The combined loss of Dnmt3a and Dnmt3b has been reported to lead to telomere elongation in cultured cells (Gonzalo et al. 2006), and we tested whether Dnmt3L deficiency affects overall telomere length in vivo. Complete loss of Dnmt3L is embryonic viable. However, the progeny of homozygous mutant females fail to develop beyond 9.5 days p.c., and homozygous mutant males are sterile (Bourc'his et al. 2001; Hata et al. 2002; Bourc'his and Bestor 2004). An independently produced knockout allele of Dnmt3L that displays identical phenotypes to those described above was used in our study (Webster et al. 2005). Dnmt $3 L^{-/-}$male germ cells (from both knockout lines) have been shown to be hypomethylated at repeats leading to widespread transcriptional reactivation and meiotic failure (Webster et al. 2005; Bourc'his and Bestor 2004). TRF analysis of spleen from Dnmt $3 L^{-/-}$ mice revealed no shift in overall telomere length in mutants compared to wild types (Fig. 2). We used adult spleen, as opposed to embryos, because Dnmt $3 L^{-/-}$mice from a heterozygous intercross survive to adulthood, and TRF length in spleen tissue represents that of the whole animal (see below). Heterogeneous high molecular weight TRFs were detected in Dnmt3L $L^{-/-}$mice, but these were also present in samples from wild-type littermates (Fig. 2). Such heterogeneous bands were first reported more than 20 years ago (Kipling and Cooke 1990; Starling et al. 1990), but it is worth highlighting that they represent a forgotten genetic heterogeneity between individuals within an inbred (often termed isogenic) colony. They are not the result of incomplete digestion, as the same TRF patterns were reproduced in independent experiments using samples from the same individuals (Online Resource 1). Family studies support the idea that these bands are not always directly inherited across generations (Fig. 3a) and that their length is established very early in development (Graakjaer et al. 2004), as the same pattern is seen in tissues representative of all three germ layers and in mature gametes (Fig. 3b; Kipling and Cooke 1990). While these findings are not novel, they do rule out the need to carry out the TRF analysis in a range of different tissue types from inbred mice.

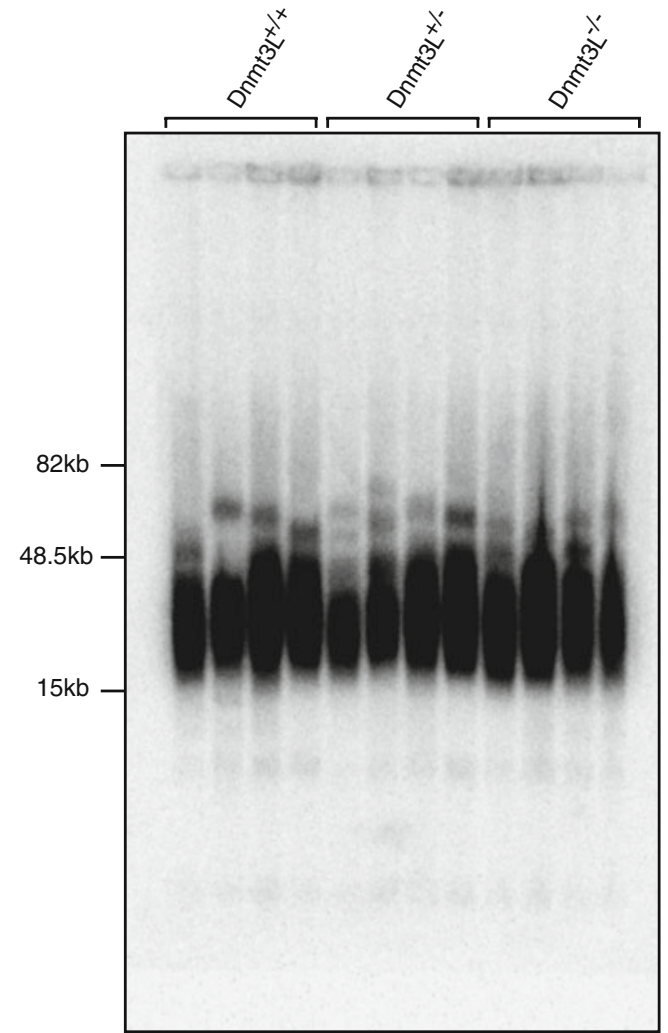

Fig. 2 Telomere length in adult spleen cells deficient for Dnmt3L. TRF results are shown for Dnmt $3 L^{+/+}, D n m t 3 L^{+/}$and $D n m t 3 L^{-/}$ spleen cells from male and female mice, 4 to 5 months of age. Individual variation in telomere length is evident from the high molecular weight bands that vary in size between each mouse

Lack of SmcHD1 does not affect overall telomere length in vivo

Smchd1 $1^{\text {MommeD1 }}$ is a mutant line that emerged from the ENU mutagenesis screen and was identified as a modifier of epigenetic gene silencing (Blewitt et al. 2008). The mutation was associated with an increase in the expression of the GFP reporter transgene. Females homozygous for the mutation die around mid-gestation from a defect in the maintenance of $\mathrm{X}$ chromosome inactivation, while males homozygous for the mutation can survive to adulthood (Blewitt et al. 2008). Smchd1 $1^{\text {MommeD1 }}$ is considered to be a null mutation, as homozygous embryos exhibit 5-fold less mRNA than wild-type littermates at 10.5 days p.c. Homozygous mutant females have placental defects and display hypomethylation at X-linked genes that are normally subject to X-inactivation. The expression of some of these genes is upregulated as a result (Blewitt et al. 2008). To test whether telomere length is altered in SmcHD1deficient cells, we performed TRF analysis on homozygous mutant female embryos at 10.5 days p.c. and on spleen 
Fig. 3 Telomere length in adult C57BL/6J mice. a TRF results for spleen from a C57BL/6J family. Sire is 12 months old, dam is 3 months old and the offspring are 2 months old. The first three offspring are male and the fourth offspring is female. A high molecular weight band is present in one offspring that is not present in either parent (arrow). b The same TRF pattern is present in mature sperm, spleen (mesoderm), liver (endoderm) and brain (ectoderm) of a male C57BL/6J mouse, 8 weeks of age

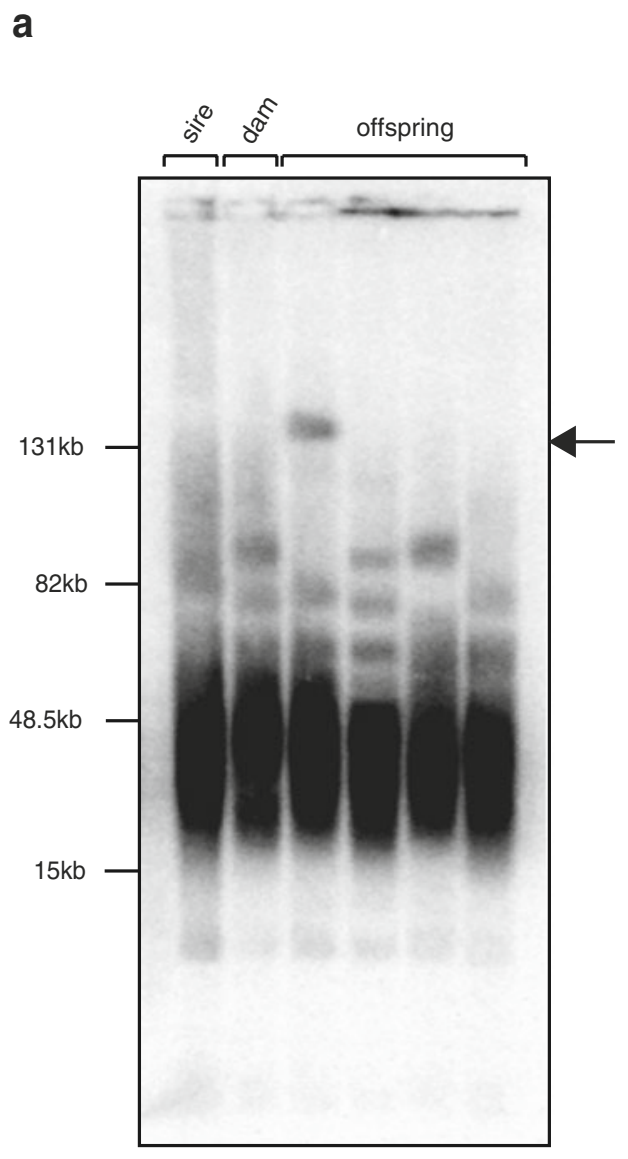

b

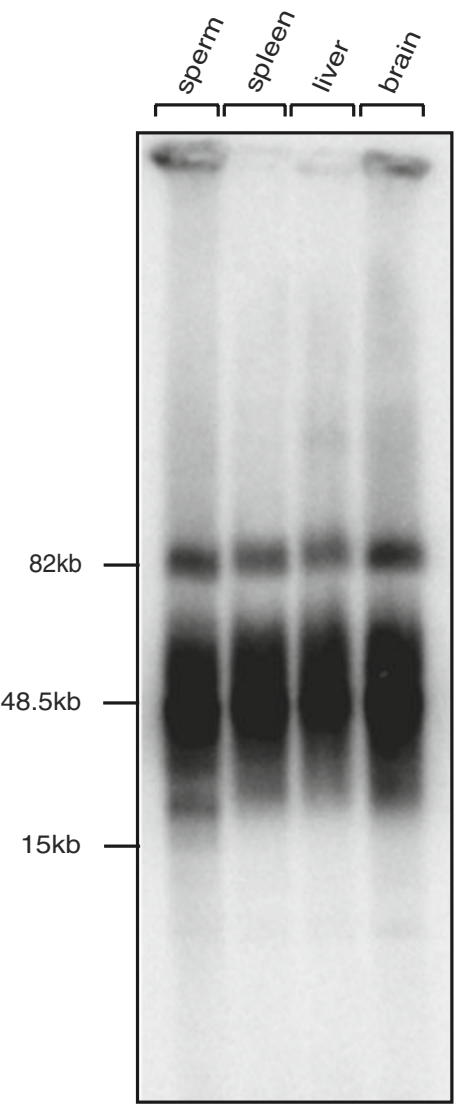

from homozygous mutant adult males (Fig. 4a, b, respectively). These mice are on a FVB/NJ strain background so the normal range of TRF length is greater than that of the $\mathrm{C} 57 \mathrm{BL} / 6 \mathrm{~J}$ strain, as mentioned previously. While we again observed inter-individual variation in TRFs, there was no apparent difference in the range of sizes in mutant compared to wild-type mice, indicating no detectable effect of SmcHD1 deficiency on overall telomere length.

Reduced dosage of Foxo3a does not affect overall telomere length in vivo

Foxo3a $a^{\text {MommeRl }}$ is a mutant line that emerged from the ENU mutagenesis screen as a modifier of epigenetic gene silencing, and the mutation was associated with an increase in expression of the GFP reporter transgene (Youngson et al. 2011). MommeR1 carries a point mutation in the Foxo3 gene which belongs to the forkhead superfamily of transcription factors. The point mutation results in a nonconservative amino acid change from the nonpolar isoleucine to polar asparagine within the highly conserved forkhead domain. In vitro transcription assays showed that the point mutation causes loss of Foxo3a transactivation activity (Youngson et al. 2011). In mammals, Foxo3a (also known as Foxo3) has been found to interact with the NADdependent deacetylase Sirtuin 1 (Sirt1; Brunet et al. 2004), the closest homolog of yeast Sir2 (Frye 1999). Palacios et al. (2010) measured telomere length in Sirt1 loss-offunction and gain-of-function mouse models. An increase of Sirtl expression leads to a higher proportion of longer telomeres in MEFs, while loss of Sirt1 leads to telomere shortening (Palacios et al. 2010). We performed TRF analysis on spleen from adult Foxo $3 a^{\text {MommeR1 }}$ homozygous mice and compared them to wild-type littermates. No overall effect on telomere length was observed (Fig. 5).

\section{Discussion}

A number of reports have implicated epigenetic processes, such as DNA methylation and histone modifications, in the regulation of telomere length in mammals (Garcia-Cao et al. 2004; Gonzalo et al. 2006; Benetti et al. 2007). Here, we assayed tissues from mouse lines carrying mutations in four modifiers of epigenetic reprogramming: Dnmt1, Dnmt3L, Smchd1 or Foxo3a. We found no overall effect on telomere 
Fig. 4 Telomere length in cells deficient for SmcHD1. TRF results are shown for $S m c h d I^{+/ 4}$, Smchd $1^{+/ M D 1}$ and Smchd1 ${ }^{M D 1 /}$ ${ }_{M D I} 10.5$-day p.c. female embryos (a) and 9-week-old male spleen (b). MD1 MommeD1
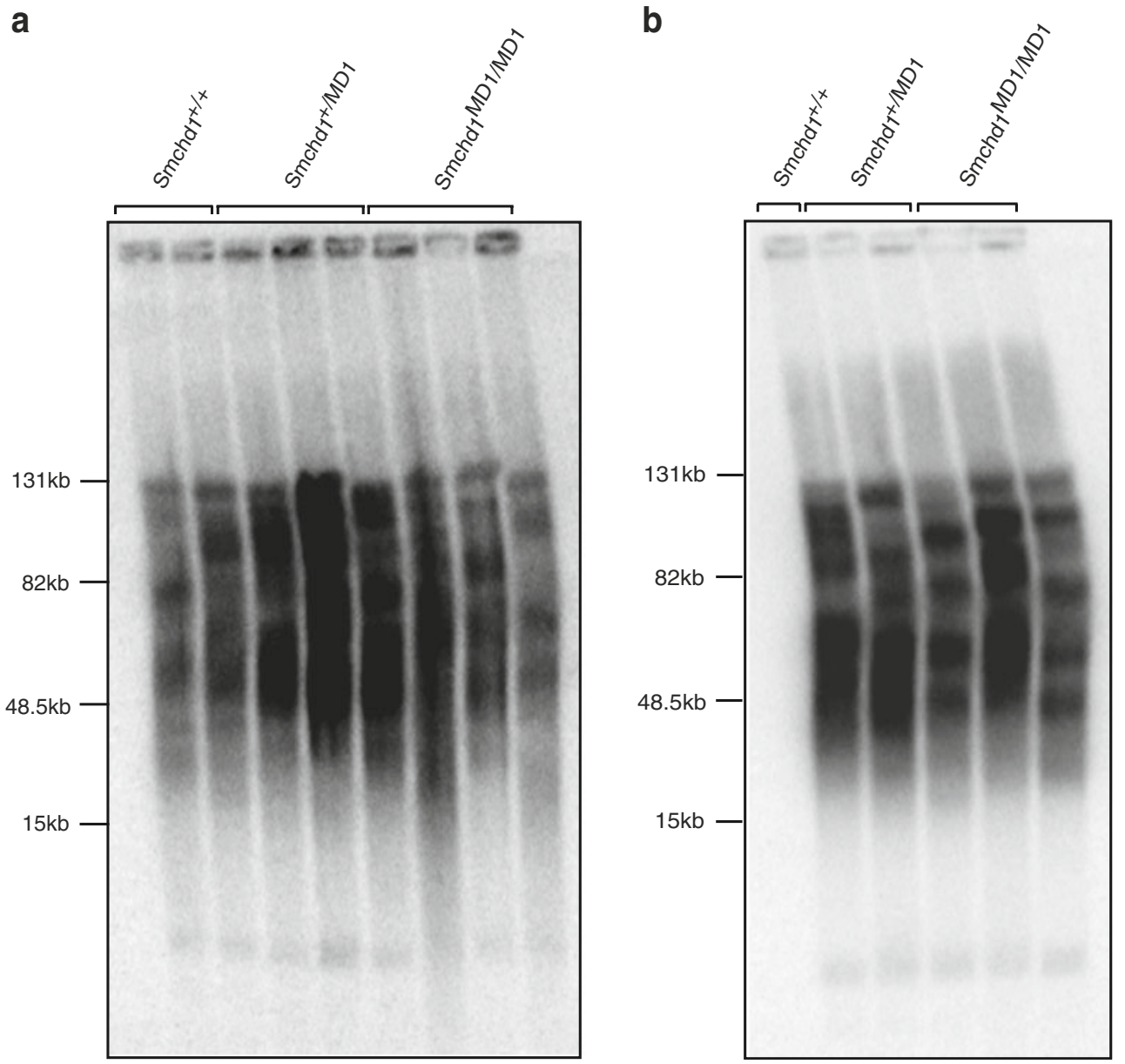

length. This lack of overall change is not due to an inability of our assay to detect such changes, as the magnitude of length changes that were previously reported in ES cells (up to $150 \mathrm{~kb}$; Gonzalo et al. 2006) can be detected in our assays (see Fig. 5).

In the case of Dnmt1, we used two independent knockdown alleles and did not see the elongation reported in Dnmt1 knockout ES cells grown in culture (Gonzalo et al. 2006). There are three possible reasons for this. One is that we have used mouse lines with incomplete loss of Dnmt1 ( $\sim 5 \%$ of wild-type levels). Another is that Gonzalo et al. (2006) used cells grown in vitro. Lastly, it is possible that the role of epigenetics in telomere length maintenance is different in pluripotent ES cells compared to differentiated cells in the embryo or adult tissue. However, the effects of various histone methyltransferase deficiencies (Suv4-20h2 alone or combined with Suv4-20h1) on telomere length were similar in cultured ES cells and cultured MEFs suggesting that, at least in this case, cell type does not matter (Benetti et al. 2007).

ES cells are derived from the blastocyst inner cell mass that eventually gives rise to the embryo, but they have also been selected for their growth characteristics in culture and may not accurately represent the situation in vivo. Support for this can be found in early studies, showing that culturing wild-type ES cells can lead to epigenetic changes and abnormal development in mouse embryos derived from these cells (Dean et al. 1998; Khosla et al. 2001). There are now a number of reports of differing methylation profiles in ES cells (both undifferentiated and differentiated) compared to their equivalent somatic tissues (Meissner et al. 2008; Brunner et al. 2009; Borgel et al. 2010), and extended ES cell growth in vitro has been shown to lead to aberrant hypermethylation at some loci (Meissner et al. 2008). Gonzalo et al. (2006) reported increasing telomere length in Dnmt3a and Dnmt3b double-null ES cells with additional passages in culture (p10-100). This lengthening in culture has also been reported in $\mathrm{Rb}^{-/-} \mathrm{Rbll}^{-/-} \mathrm{Rbl2}^{-/-}$triple knockout MEFs in which TRFs were longer in later passages compared to earlier passages (Garcia-Cao et al. 2002). Notably, TRF length of Suv39h1 and Suv39h2 double-null MEFs did not increase in later passages. These reports raise the possibility that the previously identified role for Dnmt1 in telomere length regulation in ES cells is influenced by culturing. 
Fig. 5 Telomere lengths in spleen cells deficient for Foxo3a activity. TRF results obtained with Foxo $3 a^{+/+}$and Foxo $3 a^{\text {MRII }}$ ${ }_{M R I}$ a 8- to 9-week-old female and $\mathbf{b} 9$-week-old male spleen cells. Individual variation in telomere length is evident from the high molecular weight bands that vary in size between each mouse. MRI MommeR1
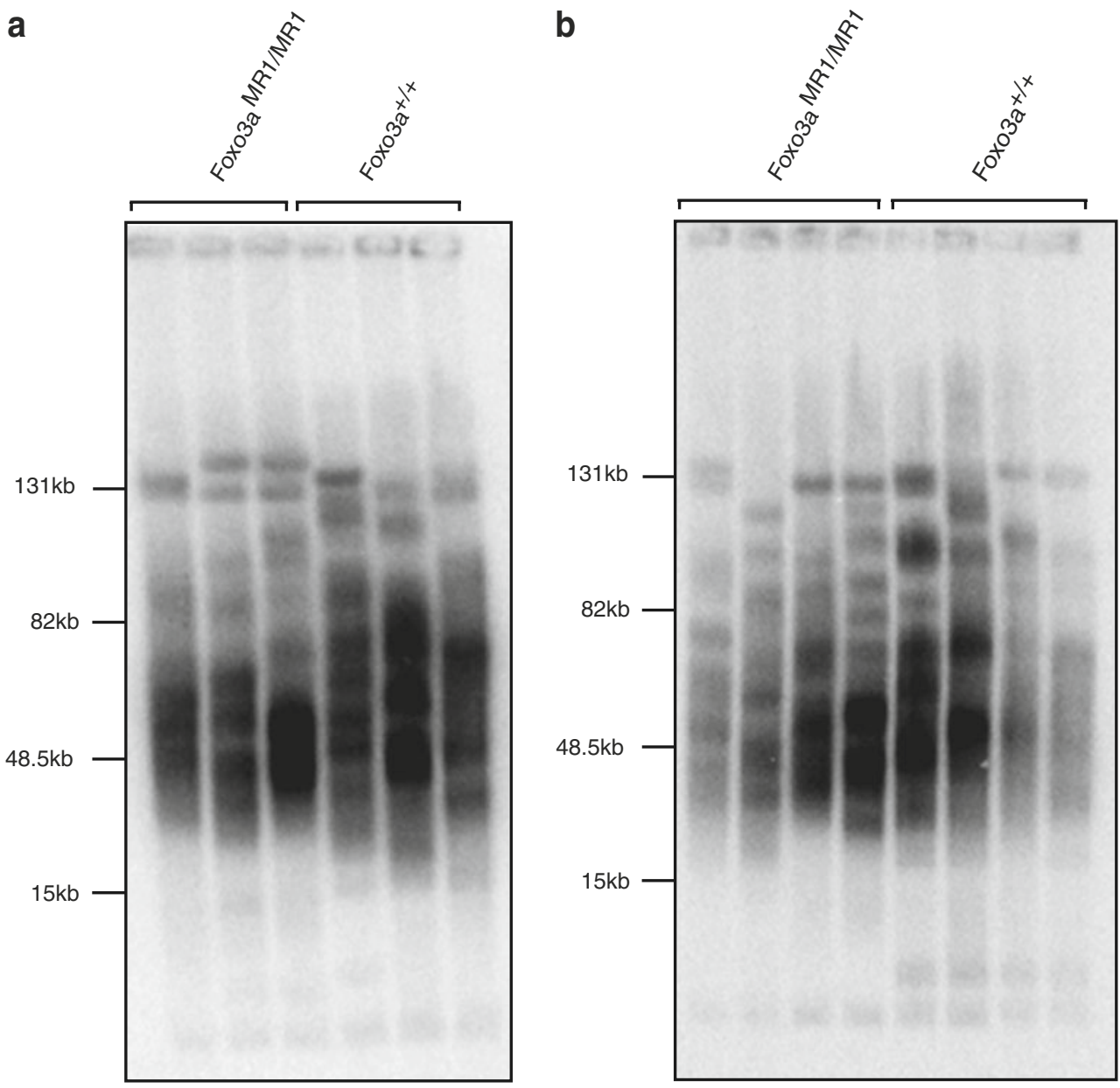

The telomere length in mice deficient for Dnmt3L, SmcHD1 or Foxo3a has not been investigated previously, and we found no overall effect in mutant compared to wild-type tissue. Together, our findings raise questions about the role of epigenetic modifiers in telomere length homeostasis in vivo.

\section{Materials and methods}

Mice and breeding strategy

The Dnmt $1^{n}$ line was purchased from the Jackson Laboratory ( $\mathrm{Li}$ et al. 1992) and has been maintained for more than 50 generations in a C57BL/6J strain background. The Dnmt $3 L^{-}$ line was a gift from Hamish Scott (Webster et al. 2005) and has been maintained for more than 20 generations in a C57BL/6J strain background. The knockout alleles Dnmt1 ${ }^{\text {MommeD2 }}$, Smchd1 $1^{\text {MommeD1 }}$ and Foxo3a MommeR1 $^{\text {are }}$ on an FVB/NJ background. Heterozygous mutant mice were produced by crossing heterozygotes with wild-type mice. Homozygous mutant mice were generated by inter-crossing heterozygous mutant mice. All homozygous mutants were first generation homozygotes.

DNA isolation and TRF analysis

Spleen, liver, brain and mature sperm cells were isolated and embedded in agarose plugs. Agarose plugs were made by following instructions from the vendor (CHEF agarose plug kit from Bio-Rad). Genomic DNA was digested with $D p n I I$ (unless otherwise stated) and electrophoresed through $1 \%$ agarose gels in $0.5 \times$ TBE using a CHEF DRII pulsed-field apparatus (Bio-Rad). Electrophoresis was carried out at $14^{\circ} \mathrm{C}$ and $4.5 \mathrm{~V} / \mathrm{cm}$ for $23 \mathrm{~h}$ at a constant pulse time of $5 \mathrm{~s}$. The gel was then stained with $1 \mu \mathrm{g}$ of ethidium bromide/ml, UV irradiated, and transferred to a Hybond-N+ membrane (Amersham Pharmacia Biotech) with $5 \times \mathrm{SSPE}\left(1 \times \mathrm{SSPE}\right.$ is $0.18 \mathrm{M} \mathrm{NaCl}, 10 \mathrm{mM} \mathrm{NaH}_{2} \mathrm{PO}_{4}$ and $1 \mathrm{mM}$ EDTA ( $\mathrm{pH}$ 7.7)). Southern blots using the radioactively labelled (TTAGGG) $)_{5}$ telomere probe were hybridized at $50^{\circ} \mathrm{C}$ in hybridisation buffer $(20 \times$ saline sodium citrate (SSC), 50× Denhardts and 20\% sodium 
dodecyl sulphate (SDS)) and washed in $2 \times \mathrm{SSC} / 0.1 \% \mathrm{SDS}$, $50^{\circ} \mathrm{C}$ and then in $0.1 \times \mathrm{SSC} / 0.5 \% \mathrm{SDS}, 50^{\circ} \mathrm{C}$.

For embryo sampling, dissections were performed at the times indicated, with vaginal plug detection representing 0.5 days post-coitum. Genomic embryonic DNA was extracted by standard protocols (Sambrook et al. 1989), with the exception of SmcHD1-deficient embryos in which the cells were embedded in agarose. Briefly, DNA was extracted from embryos by first lysing the tissue overnight at $55^{\circ} \mathrm{C}$, followed by organic extractions that were performed in equal volumes of phenol/chloroform and chloroform. High molecular weight chromosomal DNA was ethanol precipitated and resuspended in 1× TE. Genomic embryonic DNA was digested and electrophoresed as mentioned above.

Acknowledgements This study was supported by National Health and Medical Research Council Project Grants to EW. ARR is supported by an Australian Postgraduate Award. EW is supported by a National Health and Medical Research Council Australia Fellowship.

Open Access This article is distributed under the terms of the Creative Commons Attribution Noncommercial License which permits any noncommercial use, distribution, and reproduction in any medium, provided the original author(s) and source are credited.

\section{References}

Benetti R, Gonzalo S, Jaco I, Schotta G, Klatt P, Jenuwein T, Blasco MA (2007) Suv4-20h deficiency results in telomere elongation and derepression of telomere recombination. J Cell Biol 178:925-936

Bestor T, Laudano A, Mattaliano R, Ingram V (1988) Cloning and sequencing of a cDNA encoding DNA methyltransferase of mouse cells: the carboxyl-terminal domain of the mammalian enzymes is related to bacterial restriction methyltransferases. J Mol Biol 203(4):971-983

Blackburn EH (2001) Switching and signaling at the telomere. Cell 106(6):661-673

Blasco MA (2005) Telomeres and human disease: ageing, cancer and beyond. Nat Rev Genet 6(8):611-622

Blewitt ME, Gendrel A-V, Pang Z, Sparrow DB, Whitelaw N, Craig JM, Apedaile A, Hilton DJ, Dunwoodie SL, Brockdorff N, Kay GF, Whitelaw E (2008) SmcHD1, containing a structuralmaintenance-of-chromosomes hinge domain, has a critical role in X inactivation. Nat Genet 40(5):663-669

Blewitt ME, Vickaryous NK, Hemley SJ, Ashe A, Bruxner TJ, Preis JI, Arkell R, Whitelaw E (2005) An N-ethyl-N-nitrosourea screen for genes involved in variegation in the mouse. PNAS 102 (21):7629-7634

Borgel J, Guibert S, Li Y, Chiba H, Schubeler D, Sasaki H, Forne T, Weber M (2010) Targets and dynamics of promoter DNA methylation during early mouse development. Nat Genet 42(12):1093-1100

Bourc'his D, Bestor TH (2004) Meiotic catastrophe and retrotransposon reactivation in male germ cells lacking Dnmt3L. Nature 431 (7004):96-99

Bourc'his D, Xu G-L, Lin C-S, Bollman B, Bestor TH (2001) Dnmt3L and the establishment of maternal genomic imprints. Science 294 (5551):2536-2539
Brunet A, Sweeney LB, Sturgill JF, Chua KF, Greer PL, Lin Y, Tran H, Ross SE, Mostoslavsky R, Cohen HY, Hu LS, Cheng H-L, Jedrychowski MP, Gygi SP, Sinclair DA, Alt FW, Greenberg ME (2004) Stress-dependent regulation of FOXO transcription factors by the SIRT1 deacetylase. Science 303(5666):2011-2015

Brunner AL, Johnson DS, Kim SW, Valouev A, Reddy TE, Neff NF, Anton E, Medina C, Nguyen L, Chiao E, Oyolu CB, Schroth GP, Absher DM, Baker JC, Myers RM (2009) Distinct DNA methylation patterns characterize differentiated human embryonic stem cells and developing human fetal liver. Genome Res 19:1044-1056

Cesare AJ, Reddel RR (2010) Alternative lengthening of telomeres: models, mechanisms and implications. Nat Rev Genet 11:319330

Chong S, Vickaryous N, Ashe A, Zamudio N, Youngson N, Hemley S, Stopka T, Skoultchi A, Matthews J, Scott HS, de Kretser D, O'Bryan M, Blewitt M, Whitelaw E (2007) Modifiers of epigenetic reprogramming show paternal effects in the mouse. Nat Genet 39(5):614-622

Collins K, Mitchell JR (2002) Telomerase in the human organism. Oncogene 21:564-579

de Lange $T$ (2005) Shelterin: the protein complex that shapes and safeguards human telomeres. Gene Dev 19:2100-2110

Dean W, Bowden L, Aitchison A, Klose J, Moore T, Meneses JJ, Reik W, Feil R (1998) Altered imprinted gene methylation and expression in completely ES cell-derived mouse fetuses: association with aberrant phenotypes. Development 125(12):22732282

Frye RA (1999) Characterization of five human cDNAs with homology to the yeast SIR2 gene: Sir2-like proteins (Sirtuins) metabolize NAD and may have protein ADP-ribosyltransferase activity. Biochem Biophys Res Commun 260(1):273-279

Garcia-Cao M, Gonzalo S, Dean D, Blasco MA (2002) A role for the $\mathrm{Rb}$ family of proteins in controlling telomere length. Nat Genet 32(3):415-419

Garcia-Cao M, O'Sullivan R, Peters AHFM, Jenuwein T, Blasco MA (2004) Epigenetic regulation of telomere length in mammalian cells by the Suv39h1 and Suv39h2 histone methyltransferases. Nat Genet 36(1):94-99

Gonzalo S, Jaco I, Fraga MF, Chen T, Li E, Esteller M, Blasco MA (2006) DNA methyltransferases control telomere length and telomere recombination in mammalian cells. Nat Cell Biol 8 (4):416-424

Graakjaer J, Pascoe L, Der-Sarkissian H, Thomas G, Kolvraa S, Christensen K, Londoño-Vallejo J-A (2004) The relative lengths of individual telomeres are defined in the zygote and strictly maintained during life. Aging Cell 3(3):97-102

Hata K, Okano M, Lei H, Li E (2002) Dnmt3L cooperates with the Dnmt3 family of de novo DNA methyltransferases to establish maternal imprints in mice. Development 129(8):1983-1993

Khosla S, Dean W, Brown D, Reik W, Feil R (2001) Culture of preimplantation mouse embryos affects fetal development and the expression of imprinted genes. Biol Reprod 64(3):918-926

Kimura M, Stone RC, Hunt SC, Skurnick J, Lu X, Cao X, Harley CB, Aviv A (2010) Measurement of telomere length by the Southern blot analysis of terminal restriction fragment lengths. Nat Protoc 5(9): 1596-1607

Kipling D, Cooke H (1990) Hypervariable ultra-long telomeres in mice. Nature 347:400-402

Lei H, Oh SP, Okano M, Juttermann R, Goss KA, Jaenisch R, Li E (1996) De novo DNA cytosine methyltransferase activities in mouse embryonic stem cells. Development 122(10):31953205

Li E, Bestor TH, Jaenisch R (1992) Targeted mutation of the DNA methyltransferase gene results in embryonic lethality. Cell 69 (6):915-926 
Meissner A, Mikkelsen TS, Gu H, Wernig M, Hanna J, Sivachenko A, Zhang X, Bernstein BE, Nusbaum C, Jaffe DB, Gnirke A, Jaenisch R, Lander ES (2008) Genome-scale DNA methylation maps of pluripotent and differentiated cells. Nature 454 (7205):766-770

Muntoni A, Reddel RR (2005) The first molecular details of ALT in human tumor cells. Hum Mol Genet 14(suppl 2):R191-R196

Palacios JA, Herranz D, De Bonis ML, Velasco S, Serrano M, Blasco MA (2010) SIRT1 contributes to telomere maintenance and augments global homologous recombination. J Cell Biol 191 (7):1299-1313

Prowse KR, Greider CW (1995) Developmental and tissue-specific regulation of mouse telomerase and telomere length. PNAS 92 (11):4818-4822

Sambrook J, Fritsch EF, Maniatis T (1989) Molecular cloning: a laboratory manual. Cold Spring Harbor Laboratory, New York

Schoeftner S, Blasco MA (2010) Chromatin regulation and non-coding RNAs at mammalian telomeres. Semin Cell Dev Biol 21(2):186-193
Shay JW, Bacchetti S (1997) A survey of telomerase activity in human cancer. Eur J Cancer 33(5):787-791

Starling JA, Maule J, Hastie ND, Allshire RC (1990) Extensive telomere repeat arrays in mouse are hypervariable. Nucleic Acids Res 18(23):6881-6888

Webster KE, O'Bryan MK, Fletcher S, Crewther PE, Aapola U, Craig J, Harrison DK, Aung H, Phutikanit N, Lyle R, Meachem SJ, Antonarakis SE, de Kretser DM, Hedger MP, Peterson P, Carroll BJ, Scott HS (2005) Meiotic and epigenetic defects in Dnmt3L-knockout mouse spermatogenesis. PNAS 102 (11):4068-4073

Wright WE, Piatyszek MA, Rainey WE, Byrd W, Shay JW (1996) Telomerase activity in human germline and embryonic tissues and cells. Dev Genet 18(2):173-179

Youngson N, Vickaryous N, van der Horst A, Epp T, Harten S, Fleming J, Khanna K, de Kretser D, Whitelaw E (2011) A missense mutation in the transcription factor Foxo3a causes teratomas and oocyte abnormalities in mice. Mamm Genome 22(3-4):235-248 